Proceedings of the XXIII Conference on Applied Crystallography, Krynica Zdrój, Poland, September 20-24, 2015

\title{
Study of Dislocation Substructures in High-Mn Steels after Dynamic Deformation Tests
}

\author{
A. Śmiglewicz ${ }^{a}$, W. MoćKo ${ }^{b}$, K. $\operatorname{RodAK}^{a}$, I. BednarczYK ${ }^{a}$ And M.B. Jabeońska, \\ ${ }^{a}$ Silesian University of Technology, Faculty of Materials Science and Metallurgy, \\ Z. Krasińskiego 8, 40-019 Katowice, Poland \\ ${ }^{b}$ Motor Transport Institute, Jagiellońska 80, 03-301 Warsaw, Poland
}

\begin{abstract}
The article presents the dynamic mechanical properties of two types of high manganese austenitic TWIP steels. The investigations were carried out for the wide range of strain rates from $10^{-2} \mathrm{~s}^{-1}$ up to $4 \times 10^{3} \mathrm{~s}^{-1}$ using servohydraulic testing machine and split Hopkinson bar for the quasi-static and dynamic loading regime, respectively. The mechanical properties at different strain rates like yield strength and true stress were calculated out on the base of the results of impact tests. In the next step, the microstructure of the analyzed steels after different deformation rates were observed by scanning transmission electron microscopy technique in order to disclose a dislocation structures and mainly the TWIP effect. In the studies observed that with the strain rate increasing yield strength as well as true stress for 0.3 true strain increasing in both steels. The microstructure observations reveal the influence of strain rate on the structure evolution for analyzed steels.
\end{abstract}

DOI: 10.12693/APhysPolA.130.942

PACS/topics: 81.05.Bx, 81.40.-z, 68.37.Ma, 46.70.-p

\section{Introduction}

Since last year's research centres are interested to research of high-Mn steels for manufacturing of parts for automotive, railway, and military. Some of these steels belong to the group of AHS possessing together with high strength a great plastic elongation, and an ideal uniform work hardening behavior. Applying these new steels with their combination of properties allow for reducing the weight of vehicles by the use of reduced crosssection components and thus to reduce fuel consumption [1-5]. High-Mn austenitic steel is characterized by an extremely high formability and substantial strength. Capability of energy absorption is also much bigger in this case in comparison with conventional steels. Such a set of features can be explained by presence of strain mechanisms, such as creation of mechanical twins TWIP effect. For various $\mathrm{Mn}, \mathrm{Al}$, and $\mathrm{Si}$ contents, these steels have a stacking fault energy between $20 \mathrm{~mJ} / \mathrm{m}^{2}$ and $60 \mathrm{~mJ} / \mathrm{m}^{2}$ which leads to mechanical twinning until deformation [6-11]. A very important feature of high manganese steel is their high energy absorption. The energy absorption capacity of TWIP steels may reach $0.5 \mathrm{~J} / \mathrm{mm}^{3}$ at $20^{\circ} \mathrm{C}$, almost twice higher than that of conventional deep punching steel. Till now, most studies are focused on static tests, such as the tensile fatigue, welding, and deformation mechanisms. Structure studies under conditions of dynamic deformations, described in few papers play an extremely significant role in the case of these steels $[2,5,6,12-21]$. We have investigated the formation of dislocation substructures in high-Mn steels by

*corresponding author; e-mail:

magdalena.jablonska@polsl.pl scanning transmission electron microscopy (STEM) after the deformation tests with the use of the split Hopkinson bar. The dislocation substructure of high-Mn steels at intermediate strain levels and low strain rate is characterized by free dislocations with two slip detection. After the deformation with higher strain rate a significant deformation twinning and dislocation activity occurs.

\section{Experimental}

In this study two high-manganese steels $\mathrm{Fe}-25 \mathrm{wt} \%$ $\mathrm{Mn}-3 \mathrm{wt} \% \mathrm{Al}-0.3 \mathrm{wt} \% \mathrm{Si}-0.55 \mathrm{wt} \% \mathrm{C}$ (steel 1) and $\mathrm{Fe}-26 \mathrm{wt} \% \mathrm{Mn}-3 \mathrm{wt} \% \mathrm{Al}-3 \mathrm{wt} \% \mathrm{Si}-$ $0.29 \mathrm{wt} \% \mathrm{C}$ (steel 2) were used. The details of the melting, casting and rolling process of steels was presented in $[6,11,13]$. Both steels after the solutioning at $1100^{\circ} \mathrm{C}$ during $2 \mathrm{~h}$ had a monophase austenitic structure with growth twins (Fig. 1).

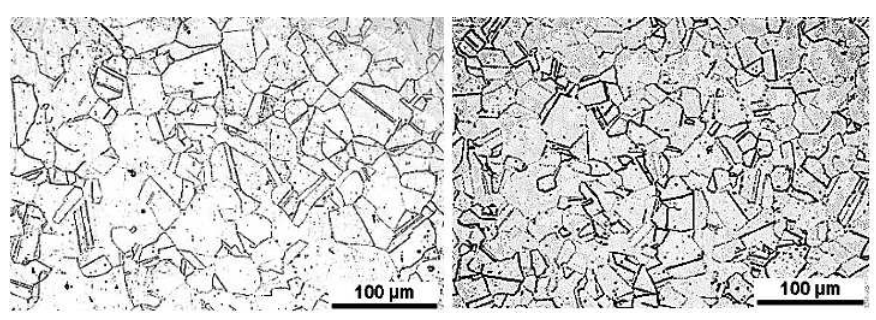

Fig. 1. The light microscopy (LM) microstructure of steel 1 (left) and steel 2 (right) after heat treatment by solution of $1100^{\circ} \mathrm{C} / 2 \mathrm{~h}$.

In order to obtain stress-strain curves of selected materials two various methods were applied. At low strain rate compression tests were conducted using a servo-hydraulic testing machine at room temperature. 
An electro-mechanical extensometer was applied for the axial strain measurements. The samples used in all of the tests performed were machined from round bars using the machining. Interfaces were lubricated using $\mathrm{MoS}_{2}$ in order to reduce friction effects between the anvil and the specimen under compression. For high strain rates split Hopkinson pressure bar methodology was applied. The test stand, presented in Fig. 2, was equipped with incident (8) and transmitter (9) bars $20 \mathrm{~mm}$ in diameter and $1000 \mathrm{~mm}$ in length, which were made of high strength maraging steel, $\sigma_{y}=2100 \mathrm{MPa}$. The signals acquired from the strain gauges (7) were amplified by the wideband bridge circuit (3) and digitized by an oscilloscope (4). The initial velocity of the striker (5), which was accelerated in a pressure gas launcher (1) was measured by two sets of diodes and photodetectors coupled to a digital counter (2). Based on the waveforms recorded by a digital oscilloscope for transmitted $\varepsilon_{T}(t)$ and reflected $\varepsilon_{R}(t)$ waves and the known cross-sectional area of the bars $\mathrm{A}$ and the specimen AS, the speed of the elastic wave propagation in the material of the bars $\mathrm{C} 0$ and the test-piece length $\mathrm{L}$, it is possible to determine stress $\sigma(t)$, strain $\varepsilon(t)$ and strain rate $\varepsilon(t)$ in the specimen using the following formulae [22]:

$$
\begin{aligned}
& \sigma(t)=E\left(\frac{A}{A_{S}}\right) \varepsilon_{T}(t), \\
& \varepsilon(t)=-\frac{2 C_{0}}{L} \int \varepsilon_{R}(t) \mathrm{d} t, \\
& \dot{\varepsilon}(t)=\frac{\mathrm{d} \varepsilon(t)}{\mathrm{d} t}=\frac{-2 C_{0}}{L} \varepsilon_{R}(t) .
\end{aligned}
$$

The dynamic tensile tests were carried out on a splitHopkinson bar tester under various strain rates $\left(1.2 \times 10^{3}\right.$, $\left.2.6 \times 10^{3}, 4.1 \times 10^{3}\right)$ at room temperature. We examined the cylinder rods with a diameter and height of $5 \mathrm{~mm}$. Both dimension errors of the cylinder rods were within $0.002 \mathrm{~mm}$. Schematic outline of the split-Hopkinson pressure bar tester was shown in Fig. 2.

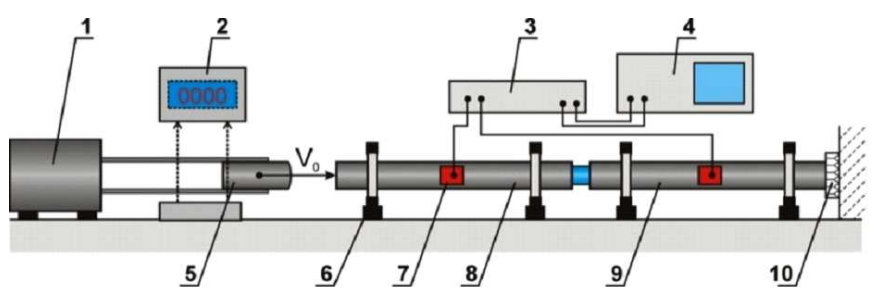

Fig. 2. Split Hopkinson tension bar testing system: 1 - pneumatic launcher, 2 - optoelectronic system of speed mesurement, 3 - strain gauge, 4 - digital osciloscope, 5 - momentum trap bar, 6 - bearing, 7 extensometer, 8 - incident bar, 9 - transmitter bar, 10 - damper [22].

As a result of dynamic deformation tests stress-strain curves were obtained. On the base of the stress-strain curves mechanical properties of steels were obtained. The structural studies were carried out by optical LM and in the submicroscopic scale, using STEM. The hardness measurement was carried out by Vickers method under a load of $2 \mathrm{~kg}$.

For dislocation microstructure characterization STEM Hitachi HD-2300A equipped with a cold field emission gun at an accelerating voltage of $200 \mathrm{kV}$ was used. Figure 3 shows the change in sample geometry during deformation and points of microstructure observations. The Vickers hardness was measured by means of a Zwick microhardness tester with use of a $2000 \mathrm{~g}$ load.

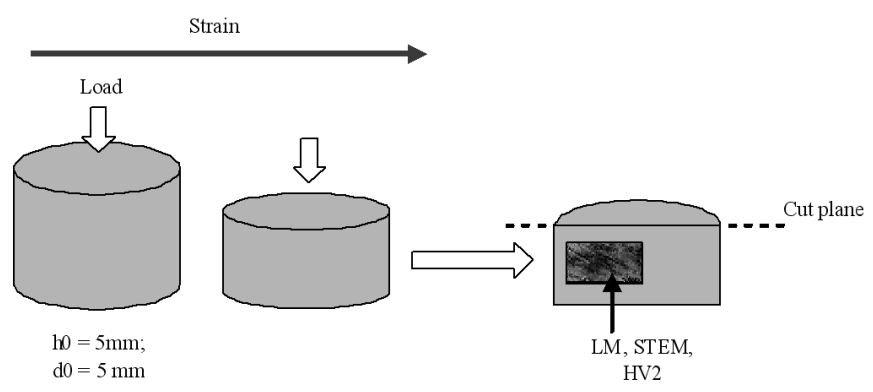

Fig. 3. Illustration of the deformation effect on change of a geometry of samples and points of STEM observations and hardness measurement.

\section{Results and discussion}

As a result of dynamic deformation tests the stressstrain curves were obtained. On the base of the curves mechanical properties like yield strength $R_{0.2}$ and true stress $\sigma$ which corresponds with 0.3 strain were calculated in Table I. With strain rate $\tau$ increase $R_{0.2}$ and $\sigma$ increases in both steels. Yield strength for steel 2 has a small higher value in comparison with steel 1 up to the $2600 \mathrm{~s}^{-1}$ strain rate. For the highest strain rate value the situation is different. True stress for steel 1 it is higher over the range of applied strain rate with respect to the steel 2 .

\section{TABLE I}

Mechanical properties of analyzed steels after the static and dynamic deformation.

\begin{tabular}{c|c|c|c|c}
\hline \hline $\begin{array}{c}\tau \\
{\left[\mathrm{s}^{-1}\right]}\end{array}$ & $R_{0.2}$, steel 1 & $R_{0.2}$, steel 2 & $\sigma^{a}$, steel 1 & $\sigma^{b}$, steel $2 \mathrm{~s}$ \\
\hline 0.01 & 395 & 412 & 1070 & 959 \\
\hline 1600 & 640 & 650 & $1020^{c}$ & $980^{d}$ \\
\hline 2600 & 725 & 735 & 1200 & 1160 \\
\hline$\sim 4000^{e}$ & \multicolumn{4}{|c}{$[\mathrm{MPa}]$} \\
\hline${ }^{a} \varepsilon=0.3, T=23^{\circ}{ }^{\circ} \mathrm{C},{ }^{b} \varepsilon=0.35, T=23^{\circ} \mathrm{C},{ }^{c} \varepsilon=0.28$, \\
${ }^{d} \varepsilon=0.25,{ }^{e} 3700 \mathrm{~s}^{-1}$ for steel $2 ; 4100 \mathrm{~s}^{-1}$ for steel 1
\end{tabular}

Figure 4 shows a microstructure of steels after deformation with strain rate $0.01-410 \mathrm{~s}^{-1}$ deformed up to strain 0.3 . In the microstructure with strain rate 0.01 for both steels (Fig. 4a,e) the dislocation structure with two slip 
systems are visible. A heterogeneous dislocation structure is formed due to the multiple character of slip. Planar slip promotes the formation of structures by the intersection of high dense dislocation walls (HDDWs) on two different slip planes. With further strain rate $\left(1600 \mathrm{~s}^{-1}\right)$ the formation of mechanical twins with primary and secondary system on the high dense dislocation matrix are visible (Fig. 4b,f). In steel 1 the twins are formed as twin bundles more often than in steel 2. The bundles are nucleated at grain boundaries and do not extend further up to the opposite grain boundaries. Higher strain rate $\left(\approx 2600 \mathrm{~s}^{-1}\right)$ leads to a further development of the twin structure. In steel 1 twins with different widths are visible in two twin systems (Fig. 4c). In steel 2 more often we observed the lamellar twin structure with similar twins widths on the deformed matrix structure (Fig. 4g). After deformation at $3500 \mathrm{~s}^{-1}$ for steel 2 - and $4100 \mathrm{~s}^{-1}$ for steel 1 we could observe the fine twin structure where there is mutual intersection of twins of similar width. The intersection are mainly the result of high strain rate (Fig. 4d,h).
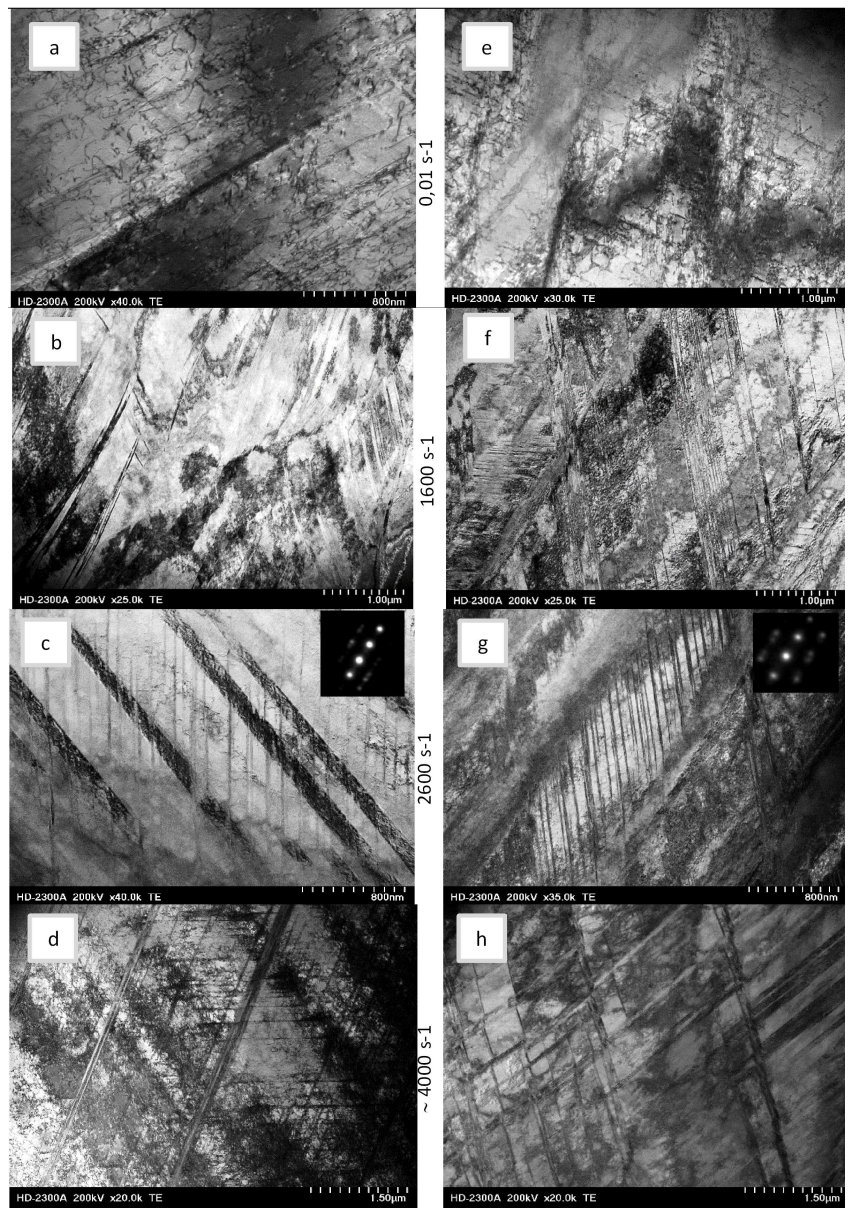

Fig. 4. Microstructure of steel $2(\mathrm{a}-\mathrm{d})$ and steel $2(\mathrm{e}-\mathrm{h})$ deformed at different strain rates.

From the above observations, it can be concluded that Vickers hardness corresponds well to the structure evolution. The development of dislocation structure during
TABLE II

Hardness data HV2 for steel 1 and steel 2 deformed at static and dynamic conditions.

\begin{tabular}{c|c|c|c|c}
\hline \hline \multirow{2}{*}{$\begin{array}{c}\text { H } \\
{\left[\mathrm{s}^{-1}\right]}\end{array}$} & \multicolumn{2}{|c}{ steel 1} & \multicolumn{2}{c}{ steel 2} \\
\cline { 2 - 5 } & $\varepsilon=0.3$ & $\sigma \approx S \mathrm{HV} \pm$ & $\varepsilon=0.3$ & $\sigma \approx S \mathrm{HV} \pm$ \\
\hline 0.01 & 305 & 11 & 280 & 14 \\
1600 & 331 & 12 & 302 & 16 \\
2600 & 390 & 15 & 355 & 18 \\
\hline 4100 & $396^{a}$ & 13 & $378^{a}$ & 16 \\
\hline
\end{tabular}

strain rate increase has generally been shown to be accompanied by an increase in hardness in Table II.

Average hardness in initial state of steel 1 was $185 \mathrm{HV} 2$ and for steel 2 was $165 \mathrm{HV} 2$. The largest increase in hardness is observed for deformation between strain rate $0.01 \mathrm{~s}^{-1}$ and $2600 \mathrm{~s}^{-1}$. In these strain rate range in the structure we observed general change. The structure visible for $0.01 \mathrm{~s}^{-1}$ strain rate is rebuilt during the strain rate increase. For example after deformation with $2600 \mathrm{~s}^{-1}$ strain rate we cannot see already the single sliding dislocations but formation of mechanical twins at two twinning systems on the high dense dislocation matrix. They did not observe a single dislocation and the presence of slip mechanism indicates the HDDW existence. The highest hardness for both steels is observed for deformation with highest strain rate used.

\section{Summary}

On the base of the results of dynamic deformation tests we note that if the strain rate increases, the yield strength as well as true stress increase for both analyzed steels. For high strain rate steel 1 has higher average properties i.e. yield strength and true stress in comparison with steel 2. Microstructure observations reveal the influence of strain rate on the structure evolution for analyzed steels. At static deformation conditions both steels are deformed by the slip mechanism. At dynamic deformation conditions (high strain rates) the twinning begins to play a main role in deformation, but evolution in the matrix is also noticeable. It is evident that applied high strain rates of the formation of mechanical twins with primary and secondary system in the whole volume of sample are visible. In steel 1 we observed twins with different widths in two twin systems rather as a lamellar structure. In steel 2 more often we observed the lamellar twins with similar widths. Deformation at highest strain rate leads to the building of fine twin structure where there is a mutual intersection twins of similar width. It can be concluded that both analyzed steels belong to the group with TWIP effect increasing the strain rate during the deformation process affecting structure development.

\section{Acknowledgments}

This work was carried out with a BK 220/RM3/2015. 


\section{References}

[1] O. Grässel, G. Frommeyer, C. Derder, H. Hofmann, J. Phys. IV 110, 383 (1997).

[2] D. Cornette, P. Cugy, A. Hildenbrand, M. Bouzekri, G. Lovato, Rev. Metall. 12, 905 (2005).

[3] G. Frommeyer, U. Brüx, Steel Res. Int. 77, 627 (2006).

[4] O. Bouaziz, S. Allain, C.P. Scott, P. Cugy, D. Barbier, Opin. Solid State Mater. Sci. 15, 141 (2011).

[5] C. Scott, S. Allain, M. Faral, N. Guelton, Rev. Metall. 6, 293 (2006).

[6] M.B. Jabłońska, Arch. Metal. Mater. 59, 1193 (2014).

[7] X. Zhi-ping, R. Xue-ping, B. Wei-ping, L. Shu-xia, Q. Hai-tao, Mater. Sci. Eng. A 530, 426 (2011).

[8] S. Lasek, E. Mazancova, Metalurgija 52, 441 (2013).

[9] E. Mazancova, I. Ruziak, I. Schindler, Archiv. Civ. Mech. Eng. 12, 142 (2012).

[10] S. Wiewiórowska, Archiv. Met. Mater. 58, 573 (2013).

[11] M. Jabłońska, A. Śmiglewicz, Def. Diff. Forum 334335, 177 (2013).
[12] A. Grajcar, P. Skrzypczyk, D. Woźniak, Arch. Metall. Mat. 59, 1691 (2014).

[13] M. Jabłońska, A. Śmiglewicz, G. Niewielski, M. Hetmańczyk, IOP Conf. Series Mater. Sci. Eng. 22, 1 (2011).

[14] A. Kokosza, J. Pacyna, Archiv. Met. Mater. 59, 1017 (2014).

[15] A. Grajcar, M. Różanski, M. Kaminska, B. Grzegorczyk, Archiv. Met. Mater. 59, 1164 (2014).

[16] W.S. Yang, C.M. Wan, J. Mater. Sci. 25, 1 (1990).

[17] S. Wiewiórowska, Z. Muskalski, Metalurgija 54, 184 (2014).

[18] R. Kuziak, R. Kawalla, S. Waengler, Archiv. Civ. Mech. Eng. 2, 103 (2008).

[19] M. Jabłońska, A. Śmiglewicz, Metalurgija 54, 631 (2014).

[20] L. Chen, Y. Zhao, X. Qin, Acta Metall. Sin. 26, 1 (2013).

[21] Z. Gronostajski, S. Polak, Archiv. Civ. Mech. Eng. 2, 57 (2008)

[22] W. Moćko, L. Kruszka, Proced. Eng. 57, 789 (2013). 